\title{
Fragmentary narrative reasoning. On the enthymematic structure of journalistic storytelling
}

Marta Zampa, ZHAW Zurich University of Applied Sciences, School of Applied Linguistics* Daniel Perrin, ZHAW Zurich University of Applied Sciences, School of Applied Linguistics

${ }^{*}$ Corresponding author: marta.zampa@zhaw.ch

\begin{abstract}
Journalists worldwide conceive of their work mostly as writing stories, because the narrative mode is extremely effective in delivering information to all social categories. Nonetheless, journalists hardly ever tell a whole story that complies with the criteria contemplated by narratology. Instead, they tell parts of a story and let the audience supply the rest, an operation made possible by the fact that narrative patterns are culturally shared by newswriters and their audiences. In this paper, we investigate some examples of fragmentary narratives as well as the journalists' strategic reasons for using them, combining approaches to storytelling and to argumentation. The case studies are taken from Corriere del Ticino, the main Italian-language newspaper in Switzerland.
\end{abstract}

\section{Keywords}

storytelling, journalistic writing, argumentation, narration, enthymeme

\section{Introduction}

Journalists worldwide conceive of their work mostly as writing stories. They look for the story in an event, focus on getting the story to the audience, and worry about stories in their texts not being clear enough (e.g., Luginbühl \& Perrin, 2011). But do journalists actually write stories? Narrative studies have long envisaged a series of characteristics for a text to be a story ${ }^{1}$, such as its structure and participants (e.g., Fludernik, 1996; Greimas, 1966; Herman, 2009). Indeed, what journalists hardly ever do is tell a whole story that complies with these criteria - both due to time and space constraints that are inherent in journalistic writing, and to the role of journalists in the public sphere. Rather, they tell parts of a story and evoke narrative patterns in the audience (Perrin \& Wyss, 2016), which allow the addressees to complete the narration-themselves.

To what purpose then do journalists make this effort? Because stories are the

1 Due to space limitations, the key concepts of narratology cannot be discussed in depth here. most effective and understandable form of communication across social groups (Perrin \& Wyss, 2016). This effectiveness results from focusing on recent aspects of socially relevant topics according to the basic narrative structure (Labov \& Waletz$\mathrm{ky}, 1967)$. As these patterns are well known in a given culture, journalists do not need to illustrate all the details and stages of the story. Instead, they can rely on the collaboration with the audience for making sense of what they are saying.

From the perspective of argumentation theory, this evocative operation consists in triggering unexpressed premises in the audience, thus creating enthymemes the typical syllogisms of rhetoric. Some premises can remain unexpressed, because they are already shared between the arguer (in this case, the journalist) and the audience of an argumentative communicative act (Aristotle, 1954; Bitzer, 1959). Indeed, leaving something implicit is widely considered an act of faith towards the rationality of the interlocutors (Jackson \& Jacobs, 1980). This form of fragmentary narrative reasoning is particularly powerful, because it makes the audience actively 
participate in the process of supporting a given standpoint: the audience supplies itself the premises that make sense of what is being said, which eventually leads to self-persuasion (cf. Bitzer, 1959).

In this paper, we claim that there is a rhetorical purpose behind the use of fragmentary narration in journalistic writing. Journalists, despite not always being aware of it, exploit the rhetorical mode of narration for its impact on the audience and leave narratives fragmentary as a strategic choice. To prove this claim, we analyze fragmentary narration in two editorials and in the corresponding reports. Building upon previous studies that consider journalistic texts enthymematic (López Pan, 2015; Zampa, 2015, 2017), we reconsider studies on journalistic writing as storytelling from an argumentation theory perspective. ${ }^{2}$ This approach shows how the two rhetorical modes of narration and argumentation - together with description and exposition - are intertwined in everyday journalistic writing, opening up to a research line that will broaden the still limited scope of studies in argumentation dealing with narration, and deepen the widespread and often superficial understanding of journalism as storytelling.

In what follows, we first outline our theoretical framework (Section 2), divided between studies on storytelling in journalism (2.1) and on argumentation (2.2). Then we explain the research methodology and describe the corpus (3). We show the argumentative power of enthymematic storytelling with the help of examples from Corriere del Ticino, the main Swiss Italian-language newspaper (4). We conclude by outlining the narrative arc as a concept to understand the interplay of rhetorical modes in public discourse, which is to a large extent stimulated by journalistic contributions (5).

2 The complementary interplay of argumentation and narration has already been discussed by Bruner (1986), who speaks of two modes of thought, the narrative and the logico-scientific (or paradigmatic) mode.

\section{Theoretical framework}

In this section, we present a concise literature review of elements from the field of narrative (2.1) and argumentative (2.2) studies that are relevant to the investigation of newswriting as fragmentary narrative reasoning.

\subsection{Storytelling in journalism}

Storytelling is an addressee-oriented semiotic activity which focuses on the process of making the communicative reconstruction of a complex discursive object understandable and thrilling by, at the same time, entertaining, informing and educating the audience. For this reason, storytelling has always played a significant role in the production of news. From ancient times on, bards and ballad mongers have wandered around from community to community, reporting events. In contemporary society, this function has been taken up by the media, so that journalists are considered the "professional story-tellers of our age" (Bell, 1991, p. 147).

Why do journalists stick to the narrative mode? Because "storytelling is effective in bringing about a sense of community - that in which listeners can easily understand and find common ground with their fellow listeners" (Barker \& Gower, 2010, pp. 305-306). A story can be indeed followed by a broad public, often regardless of the background of the individual. It is, thus, a genre that enables communication across different social layers and domains. Given that the function of journalism is exactly to synchronize society (Perrin, 2016), i.e., to communicate across diverse social groups information that is relevant for them, helping the audience to broaden their knowledge of reality (Pan \& Kosicki, 1993), it becomes clear why narratives play such a key role in journalistic text production.

For a story to be understood by an audience as wide as possible, it must be based on some fundamental elements that are shared by all members. The core features that make a discursive object a narrative are diverse. On the communicative level, they involve narrator and addressee; 
on the representation level, they include a human or anthropomorphic protagonist with intentions, a chain of events underpinned or not by a form of suspense, a depicted world (Herman, 2009). According to classical approaches, a narrative is structured in several phases. In the Labovian tradition, they entail: 1) orientation, which introduces the addressee to the whereabouts of the story; 2) complication, the events that start action in the described scenario; 3) evaluation, "that part of the narrative that reveals the attitude of the narrator towards the narrative by emphasizing the relative importance of some narrative units as compared to others" (Labov \& Waletzky, 1967, p. 32); 4) resolution, the section concluding the story; 5 ) coda, a facultative addition "for returning the verbal perspective to the present moment" (Labov \&Waletzky, 1967, p. 33).

From these core elements and following the outlined structure, basic narratives such as small and clever beats giant and clumsy are put together to the purpose of categorizing happenings and processing them cognitively in an easier way. Basic narratives are extremely powerful cognitive schemata, for they are deeply rooted in a culture and continuously reproduced in discourse (Bruner, 1991). This repetition confirms and strengthens their role in that culture. Questioning basic narratives from within the culture is thus hard to conceive, as it would mean weakening the cohesion of elements that tighten a culture together. In fact, as Lakoff (2003, p. 137) notices, "the shared rules of storytelling bind a culture together." As we will explain in Section 2.2, the same happens with endoxa.

\subsection{Argumentation}

Argumentation theory investigates how humans reasonably discuss in case of disagreement, how they express their standpoint on a given controversial issue and how they support it (cf. van Eemeren et al., 2014). Besides a long tradition in reconstructing the formal structure of argumentation (starting in ancient times with Aristotle and reviving again from the 1950s on), nowadays, studies on the actual functioning of argumentation in its contexts of use are flourishing. Journalism is one of these, with work being done especially on argumentation in the newsmaking process (Burger \& Delaloye, 2016; Luciani, Rocci \& Zampa, 2015; Zampa, 2015, 2017; Zampa \& Bletsas, 2018; Zampa \& Musi, 2016; Zampa \& Perrin, 2016). For what concerns the news product, the editorial has been at the center of scholarly attention (Gauthier, 2002; López Pan, 2015; Zampa, 2015, 2017).

The editorial is the argumentative journalistic text par excellence, featuring a commentary by an editor about a relevant event, with one or more standpoints supported by arguments based on facts and observations. Here, the journalistic pundit voices the opinion of the editorial office more than his or her own. Interestingly, although providing background information within the editorial itself would help the audience understand the position defended, editorials tend to avoid doing so. Consequently, the conclusion ends up being supported by one (or more) unexpressed premises. Editorials, as mentioned in the introduction, function thus as enthymemes (López Pan, 2015).

The enthymeme "is a syllogism based on probabilities, signs, and examples, whose function is rhetorical persuasion. Its successful construction is accomplished through the joint efforts of speaker and audience, and this is its essential character" (Bitzer, 1959, p. 408). Enthymemes are "social productions" (Jackson \& Jacobs, 1980, p. 262), which tightly bind the two parties in a communicative exchange. In the case of the editorial, the actual text constitutes the journalist's effort, whereas the readership's effort lies in providing the premises that remained implicit.

In order for this cooperation to be possible, the missing premises must be shared by both the journalist and his/ her audience, i.e., they must be endoxa. Endoxa are propositions that are "in the common opinion" and thus "generally accepted within a community" (Tardini, 2005, p. 281). As such, they are strongly bound to a specific context, and would not function as premises elsewhere. Belonging to a community indeed means 
sharing its endoxa, or - vice versa - the identity of a community or of an institution (such as a newspaper or a television channel) is defined by the endoxa its members share. Therefore, not only would outsiders not understand the reference to endoxa, but members of the community are not prone to question them, for that might mean putting themselves outside the community (cf. 2.1 on questioning basic narratives). In this perspective, Lòpez Pan's (2015) interpretation of news texts as having an epideictic function in the sense of promoting adherence to shared values and creating a sense of community is particularly fitting. ${ }^{3}$ Endoxa often remain implicit, because they are taken for granted by both parties - in Aristotle's words, "for if any one of these is well known, there is no need to mention it, for the hearer can add it himself" (Aristotle, Rhetoric, I, 1357a). This is in line with the Gricean Maxim of Quantity (1975). As Tardini (2005) notices, it would even be detrimental to verbalize these already shared premises. It would a) go back to something already established instead of going forward with discourse; b) presuppose that the audience is somehow "slow"; c) increase disagreement space. Basic narratives can be considered part of the endoxical background (see also Bird \& Dardenne, 2009).

As it emerges from this explanation, fragmented narrative communication functions only if the audience shares with the author the basic narratives according to which the story is developed. Only in this case can a reader make sense of what is written and complete the story. In order for the story to result in a felicitous communicative effort (i.e., one that informs the audience in an understandable and effective way, and that eventually also convinces it of a given position), it has to activate endoxa. We illustrate and explain such fragmented narrative communica-

3 On this issue, see also Conboy (2007) who, relying on Toulmin's model (1958), underlines that the warrants proposed in media products correspond to the knowledge shared between newsmakers and audience, and thus make standpoints acceptable for the latter. tion in Sections 4 and 5 respectively, after outlining the research tools.

\section{Research methodology and corpus description}

The data analyzed in this paper were collected within the framework of Progression Analysis (Perrin, 2003), which investigates news products as they emerge from text production processes in complex and dynamic environments. This multi-method approach (Beaufort, 1999; Dor, 2003; Sleurs, Jacobs, \& Van Waes, 2003) focuses on "the socially embedded cognitive and manifest processes of writing by individuals: their situated activity in context" (Ehrensberger-Dow \& Perrin, 2013, p. 81). The situated activity is investigated mainly by ethnographic observation, semi-structured interviews and document analysis. With Progression Analysis, data can be obtained on three levels, combining ethnography with computer-based tools. These levels are: a) the work situation, described on the basis of interviews and participatory observation; b) the text production activity, recorded with cameras at the workplace and on the screen of the journalists via a logging program; c) the writing strategies, verbalized upon reviewing the own writing process in the so-called cue-based Retrospective Verbal Protocols (from now on, RVPs), which are conducted immediately after writing is completed. Despite being an ex-post reconstruction - which might raise criticism about self-justificatory behaviors on the writers' part (Perrin, 2013, pp. 63-64) - we favor it to think-aloud protocols, which are produced during writing. The latter indeed have proven to intensively interfere with the writing itself (Janssen, Van Waes \& Van den Bergh, 1996; Levy, Marek \& Lea, 1996; Pitts, 1982; Smagorinsky, 1994, 2001).

Our team has been collecting data according to the Progression Analysis method in various Swiss newsrooms over the past twenty years. In this paper, we consider data from the latter section of the corpus, gathered in 2013 at the Swiss 
Italian-language newspaper Corriere del Ticino.

\section{Data analysis}

Editorials are an exception among journalistic products, for not only are they explicitly argumentative, but they also tend to include a complete basic narrative structure (Labov \& Waletzky, 1967), a so-called "narrative arc." Yet, to be understandable and effective, they rely on endoxa shared with the readership, featuring thus an enthymematic structure. This claim will be justified by means of the following two case studies.

The case studies considered, ${ }^{4}$ which include also the editorials' RVPs and the reports on the same topic, are the RAID ${ }^{5}$ case, on a confused international news event (4.1) and the $\mathrm{CAME}^{6}$ case, on a planned speech regarding political economy (4.2). In 4.3, the narrative structure of the editorials is enhanced and compared with that of the corresponding reports.

4 The original language of the quoted documents is Italian, translated into English by Marta Zampa and other members of the research project for previous publications. The translations can be found in the appendix.

5 The RAID case, cst_cdt_130130_0000_ OM_attaccoisraeliano_verbal_1.docx; cst_cdt_130131_0000_OM_ attaccoisraeliano_item_1.pdf; cst_cdt_130131_0000_OM_ raid_item_1.pdf. This case has been analyzed also in Zampa $(2015,2017)$ and Zampa and Musi (2016).

6 cst_cdt_130123_0000_MB_cameron_verbal_1.docx; cst_cdt_130124_0000_MB_cameron_item.pdf; cst_cdt_130124_0000_referendum_item_1.pdf. The CAME case has been analyzed in greater detail in Burger and Delaloye (2016), Zampa (2015, 2017) and Zampa and Perrin (2016). The report, though, was not taken into consideration in these publications.

\subsection{From both a fragmentarily reported $^{7}$ event ...}

The RAID editorial ${ }^{8}$ regards an alleged airstrike by Israel against Syria, in an early phase of the Syrian war. It is entitled "It's already red alert in Israel" (orig. it. "In Israele è ormai allarme rosso"), written by an experienced international news journalist, OM, on January 30,2013 , and published the day after.

This text has been chosen because it well mirrors the difficulties that can occur in the journalists' daily business of reconstructing events in a coherent and truthful journalistic way. In winter 2013, Israel was worried that a collapse of the al-Assad's regime would bring about a strengthening of Hezbollah, its historical enemy. OM's task is particularly complex, because he keeps receiving information regarding the airstrike, some confirming, others denying it. It is, therefore, difficult for him to form a well-founded opinion, for the sources are often contradictory. As a consequence, it is all the more difficult to produce an accurate and well-narrated piece. $\mathrm{OM}$ is aware of the difficulties that inhere in these kinds of events, which are, per se, not very suitable for an editorial, due to continuous updates and modifications. ${ }^{9}$

How does this story come into being? $\mathrm{OM}$ wanted to write a report on the Syrian situation in the International News page (see 4.3), but halfway through the afternoon the co-editor in chief requests him to write an editorial. He, thus, decides to use the topic for this purpose too. ${ }^{10}$ At

7 It is not the event itself what is fragmentary, it is the sources who provide fragmented and contradictory information to the journalist.

8 Full text translated into English in Appendix A.

9 0053-0065: there are cases that I don't know $\mathrm{eh} /$ votes in italy votes in france/where the commentary is much easier/because usually you try to play when all cards are on the table/ [...] /you can rarely make a commentary on exit polls/lest they are cristal clear/ [...] / eh while other situations like the one of today/are very risky for a commentary/exactly because eh during the day there were/many changes so that eh/it has to be continuously updated and say.

10 0012-0018: I already had in mind/to do 
this stage, the situation is very confused, with news about an Israeli attack at the Lebanese-Syrian border being reported by some media. ${ }^{11}$ As he has to begin writing despite the uncertainty, the journalist starts from the only confirmed event: a meeting in Kuwait City, where the international community discussed fund raising for humanitarian purposes. ${ }^{12}$ During the afternoon, various sources provide contradictory information: Israel denies having performed the attack; Lebanon denies an attack took place on its territory; Syria confirms that an air raid happened, and that it was conducted by Israel.

In addition to the piling up of information from various sources, the interpretations OM's colleagues give to the event add another layer of complication. They indeed vouch for the option that the attack might be just a rumor, spread by the Israeli government for political reasons. OM though does not follow this path, relying instead on the signs he has being collecting, which all build evidence that the attack happened. ${ }^{13}$ Indeed, a confirmation

something about syria/ [...] /and then around four o'clock the co-editor in chief came/and asked me if I could write an editorial today/and I told him I could do it on on syria/he asked me say what's new and exactly.

11 0019-0025: there were these rumors very say inaccurate/in the sense that some media ehm like le - le figaro/spoke about this israeli attack in the night/between yesterday and today/ [...] /ah ehm on the lebanese-syrian border/but it was all very vague.

12 0212-0217: therefore eh well I - I started from the most certain thing/ [...] / that was this meeting in kuwait city/ [...] / to - to raise funds/to be destined to the humanitarian field.

13 0376-0390: my colleagues and a colleague suggested me/to be say less drastic/that is he was much more cautious on this attack/he said that it might perhaps be part of/a strategy by netanyahu/now that they have to build a new government/ [...] / to do a - say favour again/the say the - the strong wing of/ [...] /of the israeli party system/while I was not so cunning/in the sense that I thought that there were too many - / too many signs that went in the same direction/that this attack actually took place. eventually comes from the Syrian army. ${ }^{14}$ Thanks to it, OM is able to put together all the pieces of the puzzle into a story that makes sense, and what seemed to be contradictory at the beginning is eventually consistent. $^{15}$

Nonetheless, the standpoint expressed in the editorial turns out to be rather weak and focused on the evaluation of Israel's behavior (D.1-D.6). ${ }^{16}$ The standpoint is expressed as plausible but not sure: "The Jewish state seems to be thus the country that is best prepared, at all levels, to face the consequences of a possible collapse of Al-Assad's regime." (D.9). Indeed, the situation is still too unclear for taking a stronger stance. Furthermore, this standpoint applies only to the first half of the text (D.1-D.9). The second half regards the humanitarian red alert discussed in Kuwait City, which is evaluated as a mere "plaster" onto a far too big wound. In spite of being the initial core of the article - and for a while the only confirmed event - this point ends up relegated to the closing.

$4.2 \ldots$ and a coherently reported event ... Let us take for comparison the CAME case, in which a pundit from the Corriere del Ticino, $\mathrm{MB}$, writes an editorial ${ }^{17}$ on a speech by the British Prime Minister David Cameron. The speech - sadly relevant now, after Brexit - regards the UK's participation in the European Union, and the conditions under which it could be continued. The journalist, who is specialized in writing editorials and masters the topic well, knew beforehand that the speech was to be held, and wished to write about it. Therefore, as soon as Cameron performed it, MB proposed the topic himself during an edito-

14 0392-0396: tonight the eh/the statement by the syrian army/has confirmed that/ [...] / that the attack took place.

15 0408-0410: when you have all puzzle pieces/ you manage to understand also those statements/that seemed to contradict each other at the beginning.

16 0277-0280: there is a stance ehm yes let's say/it is not as straight as in other commentaries/ [...] /a bit the - the evaluation of this move by israel.

17 Full text translated into English in Appendix C. 
rial conference. He already, as usual, even had a title in mind. ${ }^{18}$ Accordingly, he starts from his own hypothesis on Cameron's message and looks for confirmation in the actual speech. In argumentative terms, he collects data supporting his conclusion on Cameron's position about staying in the European Union.

For the purpose of the present article, it is particularly significant to look at how the journalist consciously appeals to the endoxical knowledge he shares with the readership. In the RVP, when reviewing the part in which he writes about behaviors that could push British citizens to reject the European Union, ${ }^{19}$ he explains that this point applies also to the Swiss. He underlines that not all readers will grasp the connection, but those who are politically more aware will. They will make a parallelism between the two countries and understand the importance of keeping track of British politics and of reading the editorial. This part of the story is not told though; it is triggered in the reader by appealing to "a series of expectations" and "a series of schemes for the interpretation of reality" (0970-0971) that are already present in the readers' minds. In argumentative terms, these schemes are endoxa that can be activated by providing the adequate data and conclusions. The case thus demonstrates how the construction of argumentation in an editorial results from the collaboration of the author and his/her audience.

\section{3 ...to fragmented stories}

Why do our two journalists tell only fragments of a story? The reasons can be found in the empirical data. Practical reasons play an obvious role. Journalists often lack time: OM, for example, finishes writing late at night and keeps changing the text because of the continuous flow of information on the airstrike. Moreover, constraints of space on the page play an

18 0102-0105: and therefore the first thing I did/according to my - my usual procedure/ me when I write an article/I have already in mind that is to say an idea.

19 0965-0966: "if one does not want to drift the british people/to vote against the adhesion." important role, as MB notices. ${ }^{20}$ More importantly, keeping storytelling fragmentary is a strategic choice. MB is aware of the rhetorical power of retrieving premises from the audience, because this makes the reader identify with the situation depicted and be willing to read the whole text. ${ }^{21}$ Furthermore, he chooses the parts of the speech that serve the purpose of building a narrative that is relevant from the Swiss viewpoint, thus adapting a foreign event to the needs and interests of his Swiss readership. To this aim, for instance, he deletes a sentence about the UK's relationship with Denmark ${ }^{22}$, but inserts a quote about a possible collaboration between the UK, Norway and Switzerland. Moreover, this latter reference seems to have not been noticed by press agencies. ${ }^{23}$ Including it serves Corriere del Ticino's goal to affirm itself as a quality newspaper at the national level, a paper capable of a little scoop. ${ }^{24}$

The narrative arc is skillfully represented in the CAME editorial. Section B includes the orientation, describing the political economic conditions that create relevance for Switzerland with respects to the UK's choices. The complication (covering all Section C) is introduced in B.12, with an explicit appeal to its meaning for Switzerland in B.13. D.1 to D.4 feature an evaluation of the speech's contents, whereas D.5 to D.6 (and the title "We have an ally in London") are an exhorting resolution. A

20 1221-1226: and here I realized/that I got to the end of the text/ [...]/therefore here one needs to do something/one needs to cut.

21 0984-0985: and obviously this arouses a - a on the reader's side/an - an identification process; 0988 you keep him stuck to the text don't you.

221298 because the reader denmark he couldn't care less.

23 0713-0717: then I discovered one thing/that agencies clearly had not discovered/and that he took stance/eh how do you say it/explicitly on the issue of switzerland.

$240731-0739$ it is simply that if the corriere del ticino/wants to be a national newspaper/ at the height at the qualitative level of other swiss newspapers/particularly my reference point/usually is the nzz [...] /it is clear that one has to make a job of this kind that is/ would not do it always but in some cases/so I believe that it is useful to do it. 
coda is present as well, in the closing sentence "We must be able to exploit this bonus properly."

The report $^{25}$ on Cameron's speech, written by a colleague from the International News page, deals with the speech and the reactions by European politicians. The latter are inserted between a summary of the speech itself (which functions as orientation) and further quotes by Cameron. They both constitute the complication. The other parts are missing, although the opening sentence - "Well, he did it" - entails an evaluative component, a tone of surprise with respect to the announcement of the referendum.

For what concerns OM, the hazard of the airstrike makes it difficult for him to tell a complete story, even in an editorial: from a fragmentarily reported event, a fragmented narrative derives. The fact that he speaks of his work as putting together puzzle pieces signals his awareness of the nature of journalistic writing. Moreover, it can be hypothesized that he avoids taking a stronger stance in an attempt not to risk compromising himself (and the newspaper) over such a delicate matter of international politics. ${ }^{26}$ For this reason, in the first half of the editorial the resolution phase is lacking. The text contains a detailed evaluation of Israel's behavior (D.1-D.8), ${ }^{27}$ which makes it possible to express a plausible standpoint. The standpoint is included in the coda (D.9), which, by mentioning the critical situation in Syria, builds a direct connection to the first sentence of the editorial (B.1). For what the second half of the RAID editorial is concerned, the orientation is limited to the minimum (E.1), but a resolution phase is present: it coincides with the ascertainment of the humanitarian red alert and with the exhortation to intervene (E.9).

25 Full text translated into English in Appendix D.

26 On the relationship between leaving information implicit and objectivity, see Zampa $(2015,2016)$.

27 0277-0280: there is a stance ehm yes let's say/it is not as straight as in other commentaries/ [...] /a bit the - the evaluation of this move by israel.
The corresponding report, ${ }^{28}$ written by $\mathrm{OM}$ as well, is focused on the air raid and does not mention the meeting in Kuwait City. Almost the whole text is devoted to the complication. The orientation is synthetically presented in the title ("Siria. Damascus accusation: Israeli air raid") and in the first line of the report ("Israel takes action in Syria"). Later on, two evaluative sentences are featured, addressing how the possession of Russian anti-aircraft missiles could affect the status quo in the area (in sections D and E). The events are accounted for with a higher degree of certainty ("the Syrian army has officially denounced a raid by Israel," "what is sure, is that the attack took place"). In the RVP, OM explains this by saying he had the chance to check the report again late that night, once a confirmation of the air raid had reached the newsroom. ${ }^{29}$ OM wrote the same story twice: the difference of genre and the circumstances of production have influenced how he recounted what happened.

\section{Conclusion}

The RAID and CAME cases are exemplary for what we found in our corpora. Based on this data, conclusions can be drawn on the interplay of narration and argumentation in journalistic work. We argue that journalistic storytelling is essentially fragmentary, with the exception of editorials, and that - in all genres - this structure is not only motivated by practical limitations, but also exploited to produce more rhetorically effective items. Besides, fragmentation is inherent in the production of journalistic texts. A journalist has to collect puzzle pieces (data) about an event, understand why and how they make sense with respect to the context in which they occur, and take a - more or less explicit -

28 Full text translated into English in Appendix B.

29 0473-0478 in the end I had to change also the - the article inside the paper/again because it was the same topic/ [...]/exactly yes eventually it arrived/the whole chronicle of the day. 
stance (Perrin, 2012) on the event (conclusion) (see also Merminod, 2016). It is in this phase that his/her - again, mostly tacit - professional knowledge comes into play: the journalist does not simply explain what happened but creates a rhetorically effective story. The story needs to follow all the requirements of the genre and its temporal and spatial limitation, with particular attention devoted to weighing which background information should be included in the text and which left implicit, trusting the audience's ability to provide it themselves. The item, thus, results in an enthymeme, whose premises are supplied by the audience to make sense of the standpoints expressed (or suggested) by the author. As can be seen in Figure 1, in general the endoxical premise remains at least partially implicit in both genres (within a dashed line). Furthermore, reports lack the conclusion (in grey).

As the data analysis has shown, the narrative structure tends to be fully present in editorials. The lack of the resolution phase in the first half of the RAID editorial can be explained with the impossibility to take a strong stance on what is reported because of the uncertainty of the events, a fact that - conversely - explains the broad evaluation of the situation. In cases where a lot of background information is needed to understand the message (such as the CAME editorial), long descriptive sections are included, so that the reader can better understand the pundit's conclusion and possibly also get to it on his/her own. In reports, on the other hand, the biggest space is devoted to the complication, with a more or less extended orientation and sometimes an evaluation - either hinted at (as in the CAME report) or drawn from ascribing an interpretation to the listed facts (as in the RAID report). Resolution and coda are lacking. Indeed, reports are enthymemes with a non-verbalized conclusion.

Figure 1 depicts the enthymematic structure with its always expressed (in white) and mostly non-expressed parts (in grey), both for editorials (left) and reports (right). Figure 2 depicts the fragmentary narrative arc, with non-expressed parts in grey and sometimes expressed ones included within a dotted line. The evaluation is represented above the arc, because it results from the external view of the author, from his/her interpretation of the facts.

The strategic reasons behind the fragmentation of the narrative structure cannot be fully revealed by looking only at the final product, where the role of the endoxical knowledge applied by the journalist as well as his/her professional skills remains overshadowed. Thorough understanding of this phenomenon results only from a joint investigation of the product and its production process. This is true all the more for cases like RAID, where the task of matching the "puzzle pieces" to build

Figure 1: Enthymematic structures

Editorials

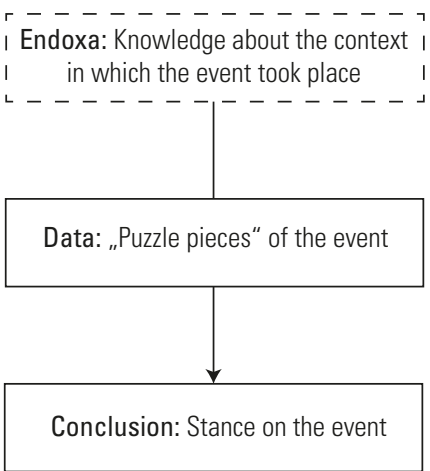

Reports

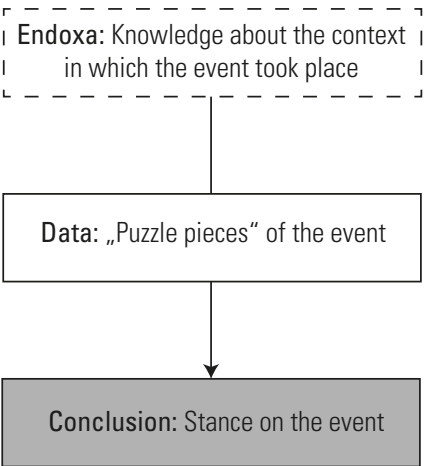


Figure 2: Narrative arc in editorials (a) and reports (b)

a) Editorials

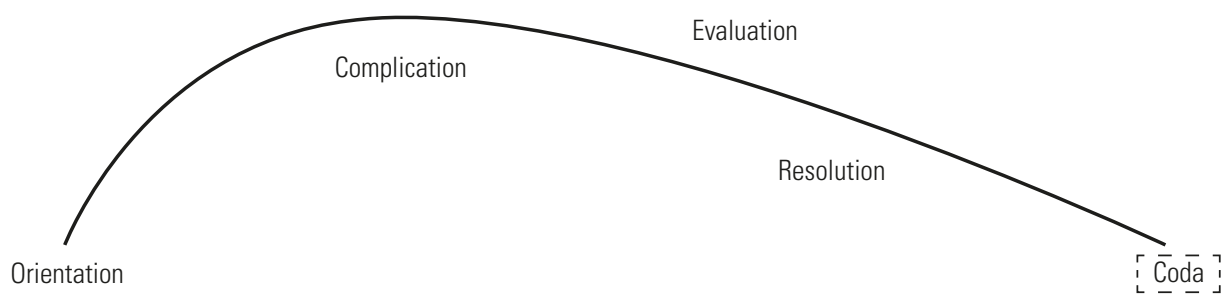

b) Reports

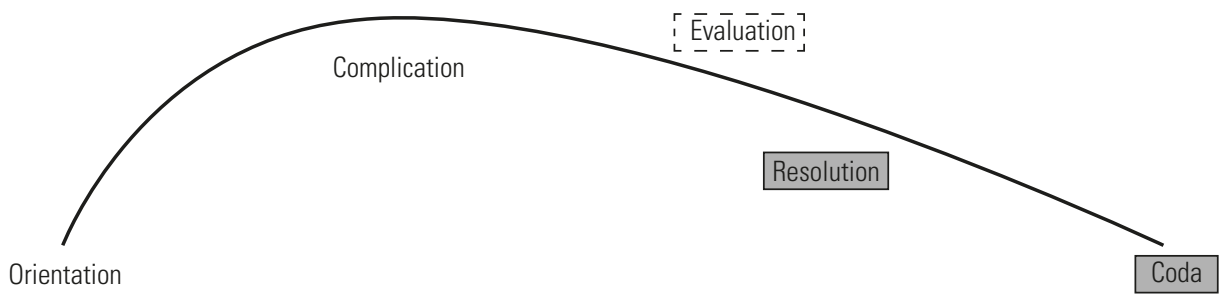

a truthful story is complicated by the uncertainty of the event and the delicacy of the topic; whereas it can be exploited more to the advantage of the writer in cases like CAME, where the storyline is well defined and the journalist can concentrate on the nuances and on addressing different levels of readership.

Despite what is custom in journalistic practice, the interplay of narration and argumentation in newswriting as a relevant source of public discourse remains a mostly unexplored territory in both fields. It is the authors' aim to pursue this line of research and attempt at unraveling the mechanisms behind and the purposes of this underestimated combination of modes $^{30}$.

30 Work on the interplay of the two modes has been conducted for other professional discourse, for example for judicial discourse (e.g., Hannken-Ilijes, 2006; von Arnauld, 2009).

\section{References}

Aristotle. (1954). Rhetoric. In W. Rhys Roberts (Ed.), Mineola. NY: Dover Publications.

Barker, R.T., \& Gower, K. (2010). Strategic application of storytelling in organizations: Toward effective communication in a diverse world. Journal of Business Communication, 47(3), 295-312. doi:10.1177/0021943610369782

Beaufort, A. (1999). Writing in the real world. Making transition from school to work. New York: Teachers College.

Bell, A. (1991). The Language of News Media. Oxford, England: Blackwell.

Bird, E. S., \& Dardenne, R.W. (2009). Rethinking news and myth as storytelling. In $\mathrm{K}$. Wahl-Jorgensen \& T. Hanitsch (Eds.), The Handbook of Journalism Studies (pp. 205-217). New York, London, England: Routledge.

Bitzer, L. F. (1959). Aristotle's enthymeme revisited. The Quarterly Journal of Speech, 45, 399-408. doi:10.1080/00335635909382374

Bruner, J. (1991). The narrative construction of reality. Critical Inquiry, 18, 1-21. doi:10.1086/448619 
Bruner, J. (1986). Actual minds, possible worlds. Cambridge, MA: Harvard University Press.

Burger, M., \& Delaloye, L. (2016). The framing of argumentation in the making of a political editorial: From normative expectations to stylistic credo of the journalists. Journal of Argumentation in Context, 5(1), 29-47. doi:10.1075/jaic.5.1.02bur

Conboy, M. (2007). The language of the news. London: Routledge.

Dor, D. (2003). On newspaper headlines as relevance optimizers. Journal of Pragmatics, 35(5), 695-721. doi:10.1016/S03782166(02)00134-0

Ehrensberger-Dow, M., \& Perrin, D. (2013). Applying a newswriting research approach to translation. Target, 25(1), 77-92. doi:10.1075/target.25.1.07ehr

Fludernik, M. (1996). Towards a "Natural" Narratology. London, England: Routledge.

Gauthier, G. (2002). L'argumentation éditoriale. Le cas des quotidiens Québécois. Studies in Communication Sciences, 2(2), 21-46.

Greimas, A. J. (1966). Sémantique structurale. Paris: Larousse.

Grice, P. (1975). Logic and Conversation. In P. Cole and J.L. Morgan (Eds.), Syntax and semantics 3: Speech acts (pp. 41-58). New York: Academic Press.

Hannken-Ilijes, K. (2006). Mit Geschichten argumentieren - Argumentation und Narration im Strafverfahren. Zeitschrift für Rechtssoziologie, 27(2), 211-224. doi:doi:10.1515/zfrs-2006-0205

Herman, D. (2009). Basic elements of narrative. Oxford, England: Wiley-Blackwell.

Jackson, S., \& Jacobs, S. (1980). Structure of conversational argument. Pragmatic bases for the enthymeme. Quarterly Journal of Speech, 66, 251-265. doi:10.1080/00335638009383524

Janssen, D., Van Waes, L., \& Van den Bergh, H. (1996). Effects of thinking aloud on writing processes. In C. M. Levy \& S. Ransdell (Eds.), The science of writing. Theories, methods, individual differences and applications (pp. 233-250). Mahwah, NJ: Erlbaum.

Labov, W., \&Waletzky, J. (1967). Narrative analysis: Oral versions of personal experience. Journal of Narrative and Life History, 7(1-4), 3-38. doi:10.1075/jnlh.7.02nar
Lakoff Tolmach, R. (2003). Narrative in the construction of social and political identity. In D. A. Tannen, James E. (Ed.), Linguistcs, language and the real world: Discourse and beyond (pp. 135-146). Washington, DC: Georgetown University Press.

Levy, C. M., Marek, J. P., \& Lea, J. (1996). Concurrent and retrospective protocols in writing research. In G. Rijlaarsdam, H. Van den Bergh, \& M. Couzijn (Eds.), Theories, models and methodology in writing research (pp. 542-556). Amsterdam, Netherlands: Amsterdam University Press.

López Pan, F. (2015). The newspaper as an epideictic meeting point. Argumentation, 29(3), 285-303. doi:10.1007/s10503-0149337-z

Luciani, M., Rocci, A., \& Zampa, M. (2015). Capturing editorial gatekeeping through the analysis of argumentation in editorial conference discussions. In M. Casoni, S. Christopher, A. Kamber, J. Miecznikowski, E. Pandolfi, \& A. Rocci (Eds.), Procedeeings of the VALS ASLA conference "Norme linguistiche in contesto", USI (Lugano, Switzerland), 12.-14. February 2014.

Luginbühl, M., \& Perrin, D. (2011). «das, was wir in der Tagesschau den Rausschmeisser nennen». Altro- und Ethnokategorisierung von Textsorten im Handlungsfeld journalistischer Fernsehnachrichten. In S. Habscheid (Ed.), Textsorten und sprachliche Handlungsmuster. Linguistische Typologien der Kommunikation (pp. 577-596). Berlin: De Gruyter.

Merminod, G. (2016). Telling stories from the newsroom. A linguistic ethnographic account of dramatisation in the broadcast news. Working Papers in Urban Language \& Literacies, 197.

Pan, Z., \& Kosicki, G. M. (1993). Framing analysis: An approach to news discourse. Political Communication, 10(1), 55-75. doi:10.1 080/10584609.1993.9962963

Perrin, D. (2012). Stancing: Strategies of entextualizing stance in newswriting. Discourse, Context \& Media, 1(2-3), 135-147.

Perrin, D. (2003). Progression analysis (PA): investigating writing strategies at the workplace. Journal of Pragmatics, 35(6), 907921. doi:10.1016/S0378-2166(02)00125-X

Perrin, D., \&Wyss, V. (2016). In die Geschichten erzählen. Die Analyse von Narration in 
öffentlicher Kommunikation. In S. Averbeck-Lietz \& M. Meyen (Eds.), Handbuch nichtstandardisierte Methoden der Kommunikationswissenschaft (pp. 241-255). Wiesbaden, Germany: Springer VS.

Pitts, B. J. (1982). Protocol analysis of the newswriting process. Newspaper Research Journal, 4(1), 12-21. doi:10.1177/073953298200400102

Sleurs, K., Jacobs, G., \& Van Waes, L. (2003). Constructing press releases, constructing quotations: A case study. Journal of Sociolinguistics, 7(2), 135-275.

Smagorinsky, P. (1994). Potential problems and problematic potentials of using talk about writing as data about writing process. In $\mathrm{P}$. Smagorinsky (Ed.), Speaking about writing. Reflections on research methodology (pp. ix-xviii). Thousand Oaks, London, New Delhi: Sage.

Smagorinsky, P. (2001). Rethinking protocol analysis from a cultural perspective. Annual Review of Applied Linguistics, 21, 233-245. doi:10.1017/S0267190501000149

Tardini, S. (2005). Endoxa and communities: Grounding enthymematic arguments. Studies in Communication Sciences, 279-294.

Toulmin, S. (1958). The uses of argument. Cambridge: Cambridge University Press.

van Eemeren, F. H., Garssen, B., Krabbe, E. C. W., Snoeck Henkemans, A. F., Verheij, B., \& Wagemans, J.H. M. (2014). Handbook of argumentation theory. Dordrecht, Netherlands: Springer.

von Arnauld, A. (2009). Was war, was ist - und was sein soll. Erzählen im juristischen Diskurs. In C. Klein \& M. Martìnez (Eds.), Wirklichkeitserzählungen. Felder, Formen und Funktionen nicht-literarischen Erzählens. Stuttgart, Germany: Springer.

Zampa, M. (2017). Argumentation in the newsroom. Amsterdam, Netherlands: John Benjamins.

Zampa, M. (2016). Objectivity in newsmaking: an argumentative perspective. In P. Bondy \& L. Benacquista, Proceedings of the $11^{\text {th }}$ International Conference of the Ontario Society for the Study of Argumentation (OSSA), $18^{\text {th }}-21^{\text {st }}$ May 2016. Windsor, ON: OSSA.

Zampa, M. (2015). News values as endoxa of newsmaking. An investigation of argumen- tative practices in the newsroom. (Ph.D.), Università della Svizzera italiana.

Zampa, M., \& Bletsas, M. (2018). On the production of a multimodal news item: an argumentative approach. Semiotica 202, 155-172.

Zampa, M., \& Musi, E. (2016). Journalistic writing "is a bit like a puzzle": keeping track of multiple voices with a combined linguistic and argumentative approach. Paper presented at the VALS ASLA conference "The process of differentiation: language practices in social interpretation," University of Geneva.

Zampa, M., \& Perrin, D. (2016). Arguing with oneself: The writing process as an argumentative soliloquy. Journal of Argumentation in Context, 5(1), 9-28. doi:10.1075/ jaic.5.1.01zam

\section{Appendix}

\section{a) The RAID editorial}

A (A.1) Syrian crisis

(A.2) It's already red alert in Israel

B (B.1) The Syrian crisis is getting worse and worse every day, for both the number of casualties and the brutality of the deeds, and the country, according to what stated on Tuesday by Lakhdar Brahimi, UNO and Arab Alliance delegate for Syria, is falling into pieces. (B.2) A rising chaos that worries the Israeli authorities a lot. (B.3) The risk indeed is that chemical weapons, but also other more sophisticated ones that constitute the equipment of the Syrian army, will end up in the hands of fearsome Islamic extremists.

C (C.1) In the night between Tuesday and Wednesday, according to sources of the Jewish state's security interviewed by the daily "Le Figaro," military airplanes bearing David's star would have launched various air raids on targets located along the Syrian-Lebanese border. (C.2) Following "Le Figaro" correspondent in Jerusalem, possible targets of the attacks could have been some convoys that carried military equipment from Syria 
to Lebanon, intended for the Islamic extremists' group Hezbollah.

D (D.1) There are contrasting versions on the events; yesterday the Lebanese state agency NNA denied news regarding an air raid at the border between Syria and Lebanon. (D.2) On the other hand on Tuesday night the same Lebanese authorities denounced the violation of their air space by Israeli airplanes. (D.3) Yesterday evening, finally, the Syrian army denounced an Israeli raid that took place at dawn against a military research center in the Damascus district. (D.4) Israeli authorities did not confirm it, but in recent days Prime Minister Netanyahu had warned on the "significant threats" that menace Israel, mentioning Iran and Syria. (D.5) Besides chemical weapons, military experts point out that Damascus' army is endowed with sophisticated weapons too, like for example ground-to-sea and ground-to-air missiles. (D.6) If this highly precise destruction tools would end up in Hezbollah's hands, vital Israeli targets like the Haifa harbor or the natural gas search wells could easily become a target. (D.7) Given the excellent intelligence capacities of the Jewish state, the red alert that went off in Israel following the worsening of the Syrian crisis has to be taken seriously. (D.8) Given Israel's determination in neutralizing serious dangers, one should not be too surprised about air raids against Syrian targets. (D.9) The Jewish state seems to be thus the country that is best prepared, at all levels, to face the consequences of a possible collapse of Al-Assad's regime.

E (E.1) From its side the international community, which until now has not been able to agree on a peaceful way out of the dramatic civil war ongoing in Syria, convened yesterday in Kuwait to offer concrete aid, at least from the humanitarian viewpoint, to the worn-out Syrian population. (E.2) Donations of more than one and a half billion dollars have been announced. (E.3) Little more than a plaster, considering the huge scourge produced by the fratricide war that has been devastating the country for more than a year. (E.4) Anyway it is a due solidarity act towards the Syrian population, brought to its knees by uninterrupted combats that, besides thousands of casualties and injured, are causing a rising flow of refugees to the neighboring countries. (E.5) But it is not only refugees who move across the frontiers of neighboring countries. (E.6) As mentioned, there is the risk that traffic of lethal weapons takes place, towards Lebanon for the benefit of Hezbollah. (E.7) Furthermore, there are numerous Islamic combatants arrived in Syria from Afghanistan and other countries in the area to fight against the Al-Assad regime. (E.8) In such a scenario it is not easy at all to urgently deliver aids to the population. (E.9) Therefore there is another red alert, the humanitarian one, that the international community is called to face up to.

\section{b) The RAID report}

A (A.1) Syria

(A.2) Damascus' accusation: Israeli air raid

(A.3) The bombardment is supposed to have taken as a target an important center for military research

B DAMASCUS (B.1) Israel takes action in Syria. (B.2) After various alerts concerning the risk that chemical weapons or other kinds of weapons could get into the hands of the Lebanese Shiite militias of Hezbollah have been launched in the last days, yesterday at dawn fighter planes of the Jewish state attacked some targets in Syrian territories. (B.3) During the whole day yesterday, various sources from diplomacy and security - which stayed anonym - have reported a bombardment on a convoy close to the border, which was shipping weapons from Syria to Lebanon.

C (C.1) Meanwhile, yesterday evening the Syrian army has officially de- 
nounced an Israeli raid - that took place early at dawn - against a military research center that had caused two casualties and five injured. (C.2) Other witnesses have earlier on reported an attack - that took place Tuesday night - to a site for the development of "non-conventional weapons" in alHameh, 15 km North-West from Damascus. (C.3) Information is confused and the Jewish state keeps silent. (C.4) But what seems certain is that the raid took place, and that between Tuesday afternoon and yesterday many Israeli jets have violated the Lebanese and Syrian air space. (C.5) An ordinary activity, yet this time on a much larger scale than usual. (C.6) At least 12 fighter planes, according to Beirut's military sources, flew across the Lebanese sky in three subsequent waves between Tuesday at 16:30 and early yesterday morning. (C.7) A circumstance confirmed also by UNO forces from Unifil in Lebanon. (C.8) This would confirm a reconstruction that the Israeli mass media have tried to make, partially slipping through the net of military censorship. (C.9) According to the Maariv and Haaretz websites, indeed, the raid took place close to the road between Damascus and Beirut. (C.10) Maariv believes it is probable that Israeli fighter planes have flown over the Golan Heights and then have headed towards the North, along the Syrian-Lebanese dividing line.

D (D.1) The state agency NNA from Beirut anyway excludes that the raid took place on Lebanese territory. (D.2) The sources that support the thesis of a raid against the cargo of weapons exclude anyway that it was the much-feared chemical weapons: it was a branch of a Russian-made anti-aircraft missiles, probably SA-7. (D.3) A weapon that, in Hezbollah's hands, could significantly alter the power balance with Israel.

E (E.1) If during the war in summer 2006 Hezbollah had fired more than 4000 rockets on the Northern part of Israel, the aviation of the Jewish state did not encounter significant obsta- cles in its repeated raids until the suburbs of Beirut. (E.2) On the contrary, an effective anti-aircraft weapon in the hands of the Shiite militians would considerably reduce the Israeli firepower. (E.3) On Sunday, Prime Minister Netanyahu had warned from the "significant threats" hanging over Israel, mentioning Iran and Syria. (E.4) Meanwhile, the army said to have repositioned two sets of anti-rocket interception systems in the Northern part of the country. (E.5) Exactly in this region, the military radio said yesterday, a high alert level is maintained, due to the fear that the "sophisticated," and not necessarily chemical, weapons are transferred from Syria to Hezbollah.

\section{c) The CAME editorial}

\section{A (A.1) Switzerland-Europe}

\section{(A.2) We have an ally in London}

B (B.1) Concerned as we are, with good reason, over the deterioration of our relationship with France and the strong Red-Green German opposition (which hold the majority at the Bundesrat and leads some strong Länder); absorbed in renegotiating the fiscal relationship with Italy, and the institutional matters with the European Union, we risk underestimating the political weight of the fiscal agreement settled with the United Kingdom last year, which came into force (together with a similar one with Austria), last January $1^{\text {st }}$. (B.2) This agreement in fact represents the revival of an old partnership with the United Kingdom as founding member of the European free trade association (EFTA) in 1960; based on a common pragmatic approach to the coexistence of the European states: first and foremost, free-trade oriented and able to preserve national sovereignty as much as possible. (B.3) EFTA has been established as a free-trade area for European countries that were not members of the European community. (B.4) Besides Switzerland and the 
United Kingdom, it encompassed the neutral Sweden and Austria (Finland since 1986), Norway, Denmark, Portugal and Iceland (member since 1970). (B.5) Great Britain left EFTA forty years ago by joining the EU in 1973, but without abandoning its own currency, the pound sterling, and refusing to belong to the Eurozone. (B.6) Despite being a full member of the European Union, London not only didn't take the step of accepting the currency, but it has also always signaled that it intended to preserve a series of national prerogatives, especially in the financial and fiscal field. (B.7) This last position has now again become topical. (B.8) In a recent article in the Herald Tribune, the previous secretary to British foreign affairs David Miliband urged the citizens of the United Kingdom (and primarily - even without mentioning him - David Cameron) not to give in to the temptation to "start a circle external to the EU one, together with Norway and Switzerland." (B.9) It's significant that he quotes Norway. (B.10) In fact, as it is well known, this country is still a member of the EFTA and the Norwegian citizens twice refused to join the EU. (B.11) Miliband's appeal is important, since the pressure on the British Prime Minister Cameron for the United Kingdom to leave the European Union's club intensified as the financial crisis in the Eurozone persisted and worsened. (B.12) Yesterday, the British Prime Minister David Cameron took a stand. His answer is important for Switzerland's interests as well, thus it deserves a close examination.

C (C.1) What did Cameron say? (C.2) That the British approach to the EU is more pragmatic ("not an end in itself") than emotional, according to the nature of the country, and that the future purpose of the European Union is not to secure peace anymore (to which the United Kingdom actively contributed, by defeating Nazism and Communism) but to secure prosperity in an extremely competitive global world. (C.3) The British Prime Minis- ter underlined that there is a gap today between the citizens and the EU, and that this crisis of democratic legitimacy has to be regulated if Europe united wants to have a future and if one does not want to drift the British people out of the EU. (C.4) "We need a structure that can accommodate the diversity of its members. Let us welcome that diversity, instead of trying to snuff it out. We cannot harmonize everything." (C.5) "The EU has consistently supported greater centralization, whereas the United Kingdom needs to safeguard its interests, its sovereignty and democratic legitimacy." (C.6) "I intend to ask that power must be able to flow back to member states" and that it is not taken away from them, "This was promised by European leaders at Laeken a decade ago. But the promise has never really been fulfilled." (C.7) Cameron undertakes to negotiate their membership with the EU to regain some national power. (C.8) At the end of the exercise, if he will be re-elected in 2015, he will announce a referendum so that the British people can decide. (C.9) "We believe in a flexible union of free member states." (C.10) If the renegotiation succeeds in protecting this principle - Cameron promised - he will commit himself with all his heart and soul to maintaining the United Kingdom within the EU, to serve the interests of Great Britain and of the EU. (C.11) For what concerns the possible partnership with Norway and Switzerland in the single market outside the UE, the British Prime Minister positioned himself in the perspective of the preeminent interests (nowadays) of the United Kingdom (C.12). "I admire those countries and they are friends of ours but we are in a different position (...). Switzerland, especially, has to negotiate access to the single market sector by sector, either accepting EU rules over which they have nothing to say or renouncing to get full access to the market in key sectors, for example financial services." 
D (D.1) From Cameron's speech, one can deduce that London's exiting from the EU club is not in the United Kingdom's interests (nor the United States', for whom it is useful to have an historical ally in the Union that defends the Atlantic interests). (D.2) But the UK's efforts to renegotiate the conditions of its membership so as to defend the sovereignty and freedom of the member states (by regaining some rights) and its request that the EU respects those who have a less centralistic vision, more flexible and respectful of diversity, seems to be very useful for Switzerland too. (D.3) All the more at a time when allies with pragmatic, freetrade oriented visions based on respect for democratic legitimation and civil rights are lacking. (D.4) As of now, for instance, (but for how long?) only Luxembourg keeps defending a large fiscal autonomy and what remains of bank confidentiality. (D.5) Under siege from several sides and with a somehow weak willpower to unite on the inside to defend our privileges as well as our historic and institutional identity, such a position on the UK's side is entirely welcome to us (even though they are a rival financial market) and provides our agreement on many points. (D.6) We have some historical affinities and common interests with London. (D.7) We must be able to exploit this bonus properly.

\section{d) The CAME report}

A (A.1) London

(A.2) Cameron has decided: the referendum has to be done

(A.3) Britons inside or outside the EU? We will know it after 2015

B LONDON (B.1). Well, he did it (B.2). The British Prime Minister David Cameron has promised a referendum in which the Britons will be able to clearly choose whether to remain "inside or outside" of the European Union - so in his awaited, many times postponed speech on Europe, performed in the City early yesterday morning (B.3). However, the vote will be possible only after London has "renegotiated" its relationship with Europe and after the 2015 elections, under the condition that the Conservatives, and Cameron, continue in the government (B.4). Thus spoke the Tory Prime Minister to the Britons, reassuring them, but warning them that it would be a definitive choice they could not walk away from, a "one-way ticket" (B.5).

C From Brussels, in a Twitter message, the president of the European Parliament Martin Schultz informed that "Europe 'à la carte' is not an option: we have to focus on work and growth more than getting lost in discussions on treaties" (C.1).

And while yesterday the British tabloids exulted, the former Labour Premier Tony Blair commented from Davos, where he is a guest of the WEF: "It is like shooting in one's head” (C.2).

"I am confident that, if a referendum will take place, the United Kingdom will decide to stay in Europe and will share the future with us," said on the contrary the Italian Premier Mario Monti, again from the WEF in Davos (C.3).

Cameron, though, from his side has assured that he wants to stay in Europe (C.4). "I want the European Union to be a success. And I want a relationship between Great Britain and the EU that sees us in the Union," he said (C.5). "I am no isolationist" and, stating his vision for a "more flexible" Europe, he said he wants "a better agreement" for London, "but also for Europe" (C.6). Which has to be different, with "power that can go back to the member states, not only get away from them" (C.7). And he continued "Countries are different. They make different choices. We cannot harmonize everything." (C.8). Because frustration grows, and today "the disappointment towards the EU is higher than ever," he warned (C.9). "I am speaking as a British Prime Minister with a positive view of the future of the European Union. A future 
in which Great Britain wants to play an active and engaged part. If we do not face the challenges, the risk is that Europe will fail and the Britons will drift towards the exit. I do not want this to happen, I want the European Union to be a success. And I want a relationship between Great Britain and the EU that sees us in the Union" (C.10). 